\title{
Effects of affective variables on L2 fossilization in adults: A critical literature review
}

\section{Jenaro A. Díaz-Ducca}

Magister(TESOL) Universidad Estatal a Distancia; jdiazd@uned.ac.cr

Recibido: 3 de agosto del 2012

\section{RESUMEN}

Esta revisión literaria considera la investigación desarrollada en los últimos 30 años sobre los efectos de las variables afectivas en el proceso de fosilización durante la adquisición de una segunda lengua (SLA) en estudiantes adultos. Primeramente, se analiza la naturaleza de la fosilización, y posteriormente, el papel de la motivación intrínseca e intrínseca, las emociones positivas y la ansiedad en el aula. Dado que ni las variables cognitivas ni intelectuales pueden cambiarse, las variables afectivas, por el contrario, deben ser utilizadas por el instructor para beneficiar y facilitar el proceso de aprendizaje de la segunda lengua.

\section{PALABRAS CLAVE}

Fosilización dellenguage, adquisición de una segunda lengua, SLA, variables afectivas, motivación, emociones, ansiedad. conocimiento, aprendizaje virtual, apoyo didáctico.
Aceptado: 5 de febrero del 2013

\section{SUMMARY}

This literature review considers research in the last 30 years about the effects of affective variables on the process of language fossilization in second language acquisition (SLA) in adults. First, the nature of language fossilization is analyzed, and then, the role intrinsic and extrinsic motivation, positive emotions, and anxiety play in the language classroom. Since cognitive and intellectual variables cannot be changed, affective variables, on the other hand, can and should be used by instructors in order to beneficiate and facilitate the learning process.

\section{KEY WORDS}

Language fossilization, second language acquisition, SLA, affective variables, motivation, emotion, anxiety.

\section{INTRODUCTION}

Learning a language is an ability that all human beings are able to develop under normal circumstances. These circumstances are both biological and environmental, but the acquisition of a native language ( $\left.\mathrm{L}_{1}\right)$ is always successful. However, learning a second language after puberty, can be completely different than learning it at a younger age: success in this case cannot be assured. In other words, even when the second language (L2) can be mastered to an efficient level, learners will never be mistaken for native speakers. According to Bley-Vroman (1989), this is what makes 
second language acquisition (SLA) completely different from child L1 development. Fossilization, which refers to the presence of incorrect linguistic features as a permanent way to speak or write, is one of the ways in which this partial acquisition of a native-like level performance in a second language is evidenced.

Moreover, extensive research has proven that in addition to cognitive factors, SLA is influenced by psychological, personal, social, and affective factors. This paper will critically review the effects of some affective variables in the adult L2 classroom, particularly on the way they may cause and prevent fossilization. These affective variables are motivation, attitude, and emotion, as described by different authors and compiled by Yokochi (2003) However, this work will focus briefly on the definition of fossilization per se, what it is and what modules of language it encompasses, while focusing on motivation and emotion only.

The bibliography reviewed here tends to be more current than "classical" theory, since it centers mainly on empirical studies and articles published in the last 20 years. Although mentions to key SLA and fossilization theories and publications will be found throughout the paper, one of the objectives of this article is to consider sources that have appeared recently and that complement rather than refute those established theories.

It should be added that fossilization is still a growing field of investigation just like many other aspects of SLA, therefore many questions and very few answers can be found. This applies mainly to the field of teaching rather than investigation. Teaching in the classroom is what makes investigation useful and investigation is what enriches teaching. Due to the magnitude of such a task, methodologies and teaching applications of affective factors on the adult L2 classroom will not be analyzed. Only their transcendence and potential as teaching tools is eventually implied.

\section{The Nature of Fossilization}

Fossilization is one of the ways in which the acquisition of an L2 is clearly partial and depending on the case, a "short of native-like proficiency" (Han, 2002). Selinker defined it as a, "mechanism [that] underlies surface linguistic material which speakers will tend to keep in their interlanguage (IL) productive performance, no matter what the age of the learner or the amount of instruction he receives in the target language." (1972)

That means that a) fossilization shows during performance $b$ ) that it is independent of the learner's age, and $c$ ) that it is independent of appropriate input (Krashen, 1982). This definition, still somewhat narrow, was re-elaborated later, taking into consideration other learner's variables,

...a permanent cessation of IL learning before the learner has attained TL norms at all levels of linguistic structure and in all discourse domains in spite of the learner's positive ability, opportunity, and motivation to learn and acculturate into target society. (Selinker \& Lamendella, 1978)

Therefore, fossilization is a permanent phenomenon. In other words, it inevitably appears during the acquisition of a second language in the vast majority of cases.

Two of the main causes of fossilization are interference from the native language and the age (critical period hypothesis). This hypothesis states that native-like level of proficiency can be developed if the learner begins to study the second language at pre-puberty. This applies particularly for pronunciation (accents). For Scovel (1988), fossilization in pronunciation can be contrasted with the "improvement in virtually all other skills being acquired by language learners... we have an interesting crossover effect between the learning of phonology... and the linguistic skills of learning new words, new inflections, new syntactic rules, 
and so forth..." On the other hand, the study of fossilization in written expression (grammar errors) in EFL college students in Costa Rica has been carefully documented by Hasbún (2008).

Under these circumstances, and as it will be argued at the end of the paper, affective variables can be a positive influence to prevent fossilization, so far as the teacher and the learner can take advantage of these variables in the classroom to delay the appearance of fossilization in the SLA process. To this extent, affective variables can be used as an important pedagogical resource.

\section{- Fossilization: Failure or Norm?}

Is fossilization a proof of failure in the acquisition of a second language? Is a foreign accent a marker of deficiency? As far as communication is possible is SLA successful or only partially so? When compared to the proficiency level of a native, an $L 2$ learner may be considered faulty in his interlanguage (IL) development. However, for Ellis, fossilized structures can be considered either errors or "correct target language forms" (1985), depending on their similitude with the target language.

Notwithstanding, even partial SLA should be seen as a successful development in comparison with mere monolinguism. The concept of multicompetence (Cook, 1991) introduces the new dimension of considering the glass "half full" instead of "half empty". Since "successful" learning is extraordinary in post-puberty SLA, "failure" rather means normal acquisition (including possible fossilization) along an IL continuum. Thus, "failure" means "normal" L2 acquisition whereas "success", exceptional learning. For the purposes of this paper, and to adhere to the current theories, fossilization or incomplete acquisition of the L2 will be considered a "failure" whereas an IL development closer to native L2 will be considered "successful".

\section{Affective Variables in SLA}

What are then the conditions of an incomplete or successful SLA? If different learners have the same opportunities to learn a language, why are some outcomes more successful than others? As Yokochi (2003) has stated, native intelligence and cognitive ability come immediately to mind, but affective variables have the same importance. Schumann (1998) points out, "I believe that emotion underlies most, if not all cognition and I will argue that variable success in second language acquisition (SLA) is emotionally driven". It is Krashen (1982) in his affective filter hypothesis who claims that one of the causes of fossilization and failure in SLA is the influence of the affective filter, when acquisition becomes impaired even under appropriate exposure to meaningful $L 2$ input. If the learner has a high affective filter, the input processed and acquired will be a lot less than that of a learner with a lower filter. Therefore, motivation and emotion are the main affective variables that will be analyzed in this paper, along with their influence (both positive and negative) on the SLA process.

\section{Motivation}

Motivation has not been acknowledged enough by researchers as an important affective variable in the L2 classroom, as Crookes and Schmidt (1991) point out. In Krashen's affective filter hypothesis (1982), fossilization is seen as a result of the learner's (lack of sufficient) motivation (the other affective variables are self-confidence and anxiety) in spite of the amount of exposition to the L2. In other words, fossilization "is due to the affective filter". "Performers with high motivation generally do better in SLA... acquirers vary with respect to the strength or level of their Affective Filters". For Cook (1996), "Motivation also works in both directions. High motivation is one factor that causes successful learning; in reverse, successful learning causes high motivation."

Although a definitive explanation of motivation is still pending, most researchers continually 
reveal new aspects of it: "In fact, every different psychological perspective of human behavior will come up with a different theory of motivation and thus in general psychology it is not the lack, but rather the abundance of motivation theories that confuses the scene". (Dornyei, 1996)

Researchers such as Tramblay and Gardner (1995), Smit and Dalton (2000), and Noels, Pelletier and Vallerand (2000) have divided motivation into extrinsic and intrinsic motivation, depending on the learner and the stage of his/ her learning: "Individuals are extrinsically motivated if they behave in certain ways in order to get external rewards or to avoid punishment; intrinsically motivated behaviours are those propelled by internal rewards such as the satisfaction of one's curiosity, or the joy at the performing a certain activity." (Noels, Pelletier and Vallerand, 2000) These two types of motivation must be seen as complementary rather than exclusive.

\section{Intrinsic motivation}

"Lack of need" (Krashen, 1985), accounts for fossilization in many cases since once the communication needs of a SL learner have been met, acquisition and learning cease. In recent research, motivation appears as the result of many other factors (Yokochi, 2003) such as purpose for learning (traveling, self-development, career success, etc.) For Bley-Vroman (1989) and Ushida (1993), performance apparently fossilizes after a learner becomes competent enough to perform the required tasks, losing all motivation to improve.

Intrinsic motivation "originates within the individual who learns for the joy, satisfaction and sense of accomplishment." (Yokochi, 2003) This means that in spite of the fact that many second language learners may never speak with the target language ( $T L$ ) community, they will feel motivated enough to keep on learning. "The inherent intrinsic motivation of human beings to encounter new stimulus events and creative challenges... is provided by the learning process itself..." (Dornyei, 1990) He states that the interest in foreign languages and cultures, along with a "desire to be more cosmopolitan" are in fact, more important than the attitudes towards the TL society.

In Dornyei's view, two other factors contribute to this will to learn: "need for achievement" and "attributions about past failures". (1990) Thus, learning a language, receiving good grades, and overcoming obstacles contribute to sustained motivation. On the other hand, bad experiences relating to SLA in the past may discourage many students to continue learning.

Another interesting point is that motivated students use a wider range of learning strategies. Okada (1996) and Samimy and Tabuse (1992) confirmed that college learners of Japanese were high achievers with strong instrumental motivation. This means that they learn the language for ulterior benefits independently of interaction with L2 speakers (Cook, 1996). The learners enriched their learning consciously through the fulfillment of activities both inside and outside the $L_{2}$ classroom. For this type of students, SLA is an experience that is not limited to the classroom. It becomes a conscious and continuous effort to have as much exposition to the target language as possible, even if $L 2$ input may be scarce or difficult to obtain in their cultural environment. Wen (1997) concludes also that "Students who were highly motivated to learn the language for certain purposes had better expectations of learning strategies and efforts." Kambon (2005) adds, "intrinsic motivational factors such as high expectations of individual effort in learning the language as well as high motivation to develop useful strategies to learn the language were found to be important predictors of interlanguage development." In short, the most significant predictors of student achievement at the intermediate level are self-determined strategies, goals, and purposes. (Wen, 1997) 


\section{Integrative motivation}

Integrative motivation was described by Gardner and Lambert (1972) as the need of the learner to communicate and take part of the target language community. For Cook (1995), it "reflects whether the student indentifies with the target culture and people in some sense, or rejects them." For Yokochi (2003), integrative motivation is a combination of intrinsic and extrinsic motivation since the language is being learned "for a specific purpose rather than 'for fun"'. In fact, "Intrinsic, integrative and extrinsic motivations may not be distinctly separate traits, but may lie along a continuum". Noels, et al. (2000) propose a "self-determination continuum". According to them, intrinsic motivation consists of three types, IM-knowledge, IM-Accomplishment, and IM-Stimulation (where IM means intrinsic motivation).

In 2001, Noels et al. announced intrinsic and integrative orientations as strongly connected. They also found an important relationship between motivational intensity, integrative orientation, and final grades. Moreover, integrative motivation was the "strongest predictor" of achievement because a higher competence is required for those who want to communicate over those who just study "for fun". The same authors (2000) also pointed out that "increased perceptions of freedom of choice and perceived competence are linked to more self-determined forms of motivation... the more internalized the reason for learning, the more comfortable and persevering students claimed to be." This means that the students' higher control over their learning and greater autonomy can guarantee in many cases, that motivation to learn will continue for a long time, and in some cases, during their whole life.

As a corollary, Smit and Dalton (2000) stated that intrinsic motives "are likely to remain fairly stable over time", whereas "extrinsic motives, on the other hand, are likely to be more variable over time depending on which external benefit the learner finds important at a given moment." This is, perhaps, one of the most important differences between intrinsic and extrinsic motivation in the long term.

\section{Extrinsic motivation}

Research has demonstrated that motivation is not static, but a dynamic process that changes according to the learner social, psychological, and affective needs. For example, Schmidt (1996) found that learners started out being intrinsically motivated, but that there existed a "steady progression with increasing proficiency toward more tangible reasons for studying English and away from purely internally driven motivational support." As it was stated before, fossilization appears in many cases when learners have acquired enough of the $L 2$ to achieve their immediate goals, losing motivation for further learning. Schumann in his pidginization theory (1998) considers that symplified versions of a language (pidgin language) develop when an adult learner has only "utilitarian" contact with the L2 community, lacking all interest to integrate or acculturate. For Van Patten (1985), a learner's IL "may pidginize if social and psychological distance are great. In other words, these learners' desire to acquire more [of the L2] than they already have is minimal".

Yokochi (2003) succinctly summarizes another basic aspect, "extrinsic and instrumental motivation originate outside the individual and are goal-achievement oriented". This means that a foreign language may be studied with the clear objective in mind of getting a scholarship or a better job in the case of the formal (classroom) learner, whereas people like immigrants may learn it (informally) only in order to function and perform daily tasks such as working, doing business, and getting along with neighbors inside the L2 community. "Learners such as these do not have a desire to lose their national identity or become "native-like" and such motivation or purpose might lead to a competency far short of near-native." (Yokochi, 2003). 
In relation to the $L 2$ classroom, Kambon in his theory of intrinsic and extrinsic motivation in interlanguage development and fossilization of error (2005) stresses some of the typical conditions in SLA that may influence extrinsic motivation, therefore causing fossilization and pidginization, "extrinsic motivational factors such as the teacher, learning materials, curriculum, classroom language, etc, lower the standards and expectations of the student to the point in which they feel that it is not obligatory to leave the L1 comfort zone of familiar words, structure, etc." According to him, the use of L1 as a "crutch" in the classroom (mainly in the Foreign Language classroom) can become a practice that de-motivates students and impoverishes their learning even in early stages.

As it will be discussed in the Conclusions of this paper, formal teaching, and SLA in the classroom may also cause fossilization in the students' IL. Under such circumstances, the appropriate use of affective variables such as motivation can help prevent fossilization to a certain degree.

\section{Emotion}

Emotion, which may seem as overstatement regarding affective variables, has scarcely been discussed in recent SLA literature, as Yokochi (2003) points out. Researchers such as Schumann (1998) and Mandler (1999) have mentioned emotion as internal factors of fossilization. Christison (1999) contributes with two important ideas regarding emotion: "there is a link between the physical pathways in the brain for transmitting emotions and the chemicals the brain produces for everyday learning and memory." Besides, he considers that negative emotions prevent blood from reaching the neocortex. In other words, the logical thinking parts of the brain lack precious blood to function correctly. As a further argument, Yokochi (2003) quotes Schumann regarding the amygdala, the gland on the temporal lobe that "assesses the motivational significance and emotional relevance of stimuli. On the basis of such appraisals, the brain allocates attention and memory resources to various problems."

Along with the positive emotions students may feel in the classroom, negative emotions like anxiety can influence SLA in different ways. In spite of the general warning of researchers against emotion manipulation, both positive and negative emotions need to be taken into account in the L2 classroom to promote learning and prevent fossilization.

\section{Positive emotions}

In the classroom the emotions students feel towards their teacher, the contents of the program, and evaluation are also very relevant on SLA. If they are positive, they may influence learning and enhance it. According to Munsell, Raven and Kinjo (1988), they review other researchers' view in favor of "supportive and warm emotional environments... The language learning should be rich in a variety of stimuli, including but not limited to information, vision, sound, imagination and intuition, social interaction, movement and reasoning."

These positive emotions are aroused by a comfortable classroom environment. For example, Dornyei (1996) mentions "appraisal of classroom environment" along with integrative motivation and linguistic self-confidence as the three components of $L 2$ motivation. Classroom environment consists of group cohesion, evalvation of the teacher (competence, rapport, personality, etc.) and evaluation of the course itself (relevance, difficulty, appeal to students, etc.) This can be translated into "student predisposition": "our study confirmed language teachers' intuitive knowledge that what goes on in the classroom will considerably affect the learner's affective predisposition." (Dornyei, Clement and Noels, 1994).

For Oxford and Shearin (1996) nurturing environment and fostering positive emotions is also very important in the classroom. The authors state that " $L 2$ learners can regress in their needs, motivation, and performance if 
their requirements for security are not met." This refers to Maslow's theory of need hierarchy. (1970) According to this theory, self actualization (including intellectual achievement) can only occur if basic needs such as the physiological, safety and security, love, esteem and others are satisfied first.

Among the studies reviewed by Yokochi (2003), Oyama's (1982) is the only one that analyzed emotion as a factor that influenced the pronunciation of immigrants. Oyama found that fossilization became more evident through the accentuation of $L_{1}$ accents as evidenced by "backsliding", that is, recurrence of structures that were supposed to be eradicated already (Han, 2005). For Oyama, students' accents became heavier when reading a paragraph than when speaking about past experiences.

\section{Negative emotions: anxiety}

The negative emotion that seems to have been more thoroughly studied is anxiety. A study by Elaine, Horwitz and Cope (1986) concluded that "teachers and students generally feel strongly that anxiety is a major obstacle to be overcome in learning to speak another language." Students reported to have felt "apprehension, worry, even dread", and also to have "difficulty concentrating, become forgetful, and have palpitations." The researchers found that anxiety develops mainly in SLA performance in the classroom. These "performance anxieties" are communication apprehension, test anxiety, and fear of negative evaluation. In other words, the affective filter rises and motivation decreases affecting self-confidence: "the language learner's self-esteem is vulnerable to the awareness that the range of communicative choices and authenticity is restricted." As Yokochi (2003) points out, anxiety not only is experienced by introverted students, due to the fact that "personalities have been known to change in the second language."

Eherman (1996) agrees with the negative effects of anxiety in a study of adult Foreign
Service Institute learners. These students considered that anxiety impaired their post training performance and reduced their self-confidence. The researcher regarded anxiety to have a "debilitating" effect on performance, except on public performances, what she called "facilitating anxiety." She disagrees, however, on the fact that introverted and sensitive students are more susceptible to anxiety since they can also become successful learners. Thus, they may restrict their learning opportunities by avoiding stressful activities like role-playing and speaking in class. She adds, "anxiety, working somewhat independently, acts to reduce the availability of cognitive and other learning resources."

Lack of self-confidence caused by anxiety is also reported by Schmidt (1996) in relation to adult EFL learners in Egypt. He found that anxious students avoided group activities and communication, preferring teacher-centered activities that were "safe" for them. On the other hand, students with a low affective filter (positive emotions) preferred communicative activities. Another important discovery is that anxiety is more frequent at the basic levels. Students who were already advanced were less anxious and enjoyed classes more. He concludes that "people engage in activities that they enjoy and that do not arouse anxiety."

Class anxiety and class risk-taking are connected according to Samimy and Tabuse (1992). For them, students who felt class discomfort (a lesser form of anxiety) were less likely to participate in risk-taking activities which may promote successful learning. In a similar way, Schmidt, Maclntyre and Charos found in 1996 that learners who are less anxious are more integratively motivated and therefore, more likely to look for interaction with the target language community. They also concluded that language anxiety had a direct influence on "willingness to communicate" and once again, resulted in lack of confidence. 
To summarize, anxiety apparently increases the affective filter, decreases self-confidence and risk-taking, and reduces motivation, which negatively influences the learning process. Since precious learning opportunities are missed inside and outside the classroom in order to avoid anxiety, fossilization and failure in SLA may occur more frequently.

\section{CONCLUSIONS}

\section{Pedagogical Considerations: Does Formal Teaching Aid Acquisition?}

In general, it has been widely discussed in SLA literature if formal instruction, i.e., classroom education, can prevent fossilization. For Ellis (1988), once learners have achieved adequacy in communication, they "may need form-focused instruction to make them aware of grammatical features that have little communicative importance and yet constitute target language forms. In other words, formal instruction serves to prevent fossilization..." According to Han (2004) there exists an "if-then type of conception" that if formal instruction is not provided, fossilization will occur. This conception, as she calls it, "has also been a major driving force behind the revival of general interest in grammar teaching since the early 1980's. (Van Patten, 1980 in Han, 2004)

Nevertheless, many researchers warn about the effects of formal instruction, "not all instruction is expected to be equally successful, and some actually impede success" (Bley-Vroman, 1989). Pica (1994) shares the same opinion. In contrast, Long (1983), after reviewing 13 studies by other researchers on the effects of formal instruction, concludes that "there is considerable (albeit not overwhelming) evidence that instruction is beneficial for the children as well as adults, for beginning, intermediate, and advanced students; on the integrative as well as discrete-point tests, and in acquisition-rich as well as acquisition-poor environments." Han (2004) adds, "moreover, the benefits of instruction appear to be the strongest at beginning levels and in acquisition-poor environments."

\section{- Importance of Affective Variables in the L2 Classroom: Can Fossilization Be prevented?}

Throughout this literature review, affective variables overlap and seem to have an important role of SLA in the classroom, and indirectly, also on the incidence of fossilization. In spite of the absence of conclusive information in the SLA field, some elements derived from empirical research and especially the teachers' experience in the classroom should not be discarded.

In other words, if cognitive and biological aspects of fossilization cannot be changed, affective variables can (and should) be used as precious teaching resources. That is, affective variables ought to be considered pedagogical resources to atone for the influence of cognitive factors in favor of successful SLA. Students who are positively motivated towards the L2 and the culture, the teacher, the contents of the program, and the activities developed in class may benefit more than those that are not adequately motivated or those who hold negative attitudes. In Foreign Language Acquisition, in particular, where the classroom stands as the main source of $L 2$ input, students and teachers need to make the most out of their classes in order to transform learning into a pleasant, and overall, successful process.

In poor countries such as Costa Rica, where technological resources are still relatively scarce in the classroom, teachers must appeal to as many pedagogical tools as they can. If non-technological resources such as students' motivation and positive emotions are seen in this light, formal instruction may be more effective in the L2 classroom and beyond. As it 
has been shown in this paper, motivated students will look for more opportunities to learn the language and to interact with L2 speakers outside the classroom, enriching their learning and thus motivating them to learn even more. Once again, it can only be guessed that integratively motivated students will be interested in learning and improving for a very long time, preventing the appearance of fossilization in early stages of learning. This, of course, will depend on every person, since all learners are different. Conclusive information is still lacking.

\section{- Recommendations for Further Fossilization and Affective Variables Studies}

SLA processes in general and fossilization in particular still remain to be extensively researched. Due to the fact that conclusive information on fossilization is not available, the opinion of experts should be quoted to close this review. In the case of fossilization, specialists such as Han have suggested two main directions of research: longitudinal studies that describe and document cases of fossilization. The other, are cross-sectional or similar studies that address the "alleged causal factors" of fossilization (Han, 2004). She concludes, "In a nut shell, both descriptive studies and experimental studies are warranted to enhance the general understanding of fossilization; they should be complementary to each other in that the former directly contributes to the ongoing empirical database, and the latter investigates the etiology. (2004)

\section{REFERENCES}

Abu-Rabia, Salim. (1996). Attitudes of Arab Minority Students in Israel and Canada Toward Learning a Second Language. In The Journal of Social Psychology, 136.4:541-543.

Bley-Vroman, Robert. (1989). The logical problem of foreign language learning. In Linguistic Per- spectives on Second language Acquisition, pp.44-49.

Cook, Vivian. (1996). Second Language Learning and Language Teaching. Edward Arnold Publishers Limited, pp. 115-121.

Christison, Mary Ann. (1999). Applications of BrainBased Research to Second Language Teaching and Learning: Part 1. In Tesol Matters, 9.2:1,8.

Crookes, G., \& Schmidt, R. (1991). Motivation: Reopening the research agenda. In Language Learning, 41(4), pp. 469-512.

Dornyei, Zoltan. (1990). Conceptualizing motivation in foreign-language learning. In Language Learning, 40.1: 45-75.

(1994). Motivation and Motivating in the Foreign Language Classroom. In Modern Language Journal, 78.3:273-283.

(1996). Moving Language Learning Motivation to a Larger Platform for Theory and Practice. In Rebecca L Oxford (Ed.), Learning Motivation: Pathways to the New Century, pp. 71-80.

Ellis, R. (1988). Are Classroom and Naturalistic Acquisition the Same? In Studies in Second Language Acquisition 11. pp. 305-328.

Elliott, A. Raymond. (1995). Field Independence/ Dependence, Hemispheric Specialization, and Attitude in Relation to Pronunciation Accuracy in Spanish as a Foreign Language. Modern Language Journal. 79.3:356-71.

(1995). Foreign Language Phonology: Field Independence, Attitude, and the Success of Formal Instruction in Spanish Pronunciation. Modern Language Journal, 79-4:53-42.

Gardner,R.C. (1980). On the validity of affective variables in second language acquisition: Conceptual, contextual, and statistical considerations. Language Learning, 30.2:255-270.

Greenspan, S. I. (1997). The growth of the mind. Reading, MA: Addison Wesley. Pp. 1-6.

Han, ZhaoHong. (2004) Fossilization in Adult Second Language Acquisition. Multilingual Matters Limited. pp. 1-15, 124-161. 
Hasbún, Leyla. (2008). Fossilization and Acquisition: A Study of Learner Language. In Filología y Lingüística Journal, XXXIII (1): 113-129.

Kambon, Obadele. (2005). Theory of Intrinsic and Extrinsic Motivation in Interlanguage Development and Fossilization of Error. http://www.assatashakur.org pp. 1-5.

Krashen, Stephen. (1982). Principles and Practice in Second Language Acquisition. Pergamon Press. p. 30.

(1985). The Input Hypothesis: Issues and Implications. Longman. p. 43-46.

Lin, Yue-Hong. (2005). Direcciones para los futuros estudios de la estabilización / fosilización. Revista redELE. Number 3. pp. 1-3.

Lyons, Carol A. (1999). Emotions, Cognition, and Becoming a Reader: A Message to Teachers of Struggling Learners. Literacy Teaching and Learning. Volume 4, Number 1, p. 72.

Munsell, Paul E., Rauen, Margarida Gandara, \& Kinjo, Mamoru. (1988). Language Learning and the Brain: A Comprehensive Survey of Recent

Noels, Kimberly A., Clement, Richard, \& Pelletier, Luc G.(2001). Intrinsic, Extrinsic, and Integrative Orientations of French Canadian Learners of English. Canadian Modern Language Review 57 (3): 424-442.

Noels, Kimberly A., Pelletier, Luc G., \& Vallerand, Robert J. (2000). Why are you learning a

second language? Motivational Orientations and Self-Determination Theory. Language Learning, 50.1:57-85.

Oyama, S. (1982). A sensitive period for the acquisition of a nonnative phonological system. In S. Krashen, R. Scarcella and M. Long (eds.), Linguistic Perspectives on Second Language Acquisition (pp20-38).

Samimy, Keiko Komiya, Tabuse, Motoko. (1992). Affective Variables and A Less Commonly Taught Language: A Study in Beginning Japanese Classes. Language Learning, 42.3:377-398.

Schumann, J.H. (1998). The Neurobiology of Affect in Language. Language Learning, 48: Supplement 1.

Selinker, . (1978). Two Perspectives on Fossilization in Interlanguage Learning. Interlanguage Studies Bulletin, 3.2: 76-99.

Smit, Ute \& Dalton, Christiane. (2000). Motivational Patterns in Advanced EFL Pronunciation Learners. IRAL, International Review of Applied Linguistics in Language Teaching, 36.3/4:229.

Ushida, Ema. (1993). Acculturation Theory and Linguistic Fossilization: A Comparative Case Study. CLC Occasional Paper. p. 17.

Yokochi, Laura. (2003). Affective Variables in Second Language Acquisition: A Critical Review of the Literature. West Virginia University, online publication. Pp. 1-3, 14-29. 